\title{
JM
}

Volume 6 No. 1 (April 2018)

(C) The Author(s)

\section{GAMBARAN PELAKSANAAN PEMBERIAN ASI EKSKLUSIF PADA BAYI 6-12 BULAN DI WILAYAH KERJA PUSKESMAS TALANG LEAK KABUPATEN LEBONG TAHUN 2017}

\section{DESCRIPTION OF THE IMPLIMINTATION OF EXCLUSIVE BREAST FEEDING FOR INFANTS 6 TO 12 MONTHS IN THE WORK AREA OF PUSKESMAS TALANG LEAK LEBONG DISTRIC IN 2017}

\author{
VENTI KUSUMA WIJAYANTI \\ DOSEN PRODI DIPLOMA III KEBIDANAN FIKES UNIVED BENGKULU \\ Email : ventikusuma7@gmail.com
}

\begin{abstract}
ABSTRAK
Latar belakang penulis dari data Dinas Kesehatan Provinsi BengkuluASI Eksklusif tertinggi yaitu wilayah Lebong 2.573 (74\%), dan yang terendah Kota Bengkulu 1.376 (38\%). Untuk wilaya Lebong, Puskesmas yang memiliki ASI ekslusif tertinggi yaitu Muara Aman sebesar 234 bayi (82,7\%), Sedangkan Puskesmas yang memiliki cakupan ASI Eksklusif terendah di Puskesmas Talang Leak yaitu hanya 40 bayi (54\%).Tujuan yang akan dicapai adalah pelaksanaan pemberian ASI Eksklusif pada bayi usia 6-12 bulan di wilayah kerja puskesmas Talang Leak Kabupaten Lebong tahun 2017.Metodepenelitian yang digunakan adalah deskriptif,menggunakan tehnik Total Sampling, penelitian dilaksanakan di Wilayah Kerja Puskesmas Talang Leak Kabupaten Lebong,pengambilan sampel secara keseluruhan ibu yang mempunyai bayi usia 6-12 bulan yang menyusui berjumlah 40 bayi.Hasil penelitian menunjukkan bahwa dari 40 responden, hampir setengah bayi $(22,5 \%)$ yang tidak ASI Eksklusif. Dan Hampir seluruh bayi (77,5\%) yang ASI Eksklusif.Kesimpulan dan saran, hampir setengah bayi yang tidak asi ekslusif dikarenakan ibu masih memberi makanan tambahan seperti air putih/air mineral, ada yang memberikan madu sebagai tradisi adat setempat.Hampir seluruh yang murni ASI eksklusif tanpa diberikan apapun pada bayi dari 40 responden. Saran, bagi Akademi Kebidanan Dehasen Bengkulu dapat dipakai dan dijadikan bahan referensi dan bacaan tambahan diperpustakaan,bagi puskesmas Talang Leak sebagai masukan dan bahan informasi bagi petugas dalam memberikan penyuluhan tentang ASI ekslusif pada bayi 6-12 bulan,bagi penulis, sebagai tolak ukur atas kemampuan penulis agar dapat menerapkan pelaksanaan pemberian ASI ekslusif pada bayi 6-12 bulan.
\end{abstract}

Kata Kunci : Asi Ekslusif.

\begin{abstract}
Based on the data from the Provincial Health Office Bengkulu the highest percentage of exclusive breastfeeding in Lebong area of 2.573 (74\%), and the lowest was in Bengkulu City by $1.376(38 \%)$. InLebong, the highest rank of exclusive breastfeeding health center is in MuaraAman (23.7\%), whereas the lowest Exclusive Breastfeeding coverage was in Talang Leak Health Center which was only 40 babies (54\%). The goal to be achieved is the implementation of Exclusive Breastfeeding in infants aged 6-12 months in the working area of
\end{abstract}


Talang Leak Health Center in LebongDistrict in 2017.The research method used was descriptive, using Total Sampling technique, the research was conducted in the Working Area of Talang Leak Health Center of Lebong District, the overall sampling of mothers with babies aged 6-12 months who breastfed amounted to 40 babies. The results showed that from 40 respondents, almost half of infants $(22.5 \%)$ were not exclusively breastfed. And almost all infants $(77.5 \%)$ were Exclusive breastfed.Conclusions and suggestions, almost half of infants who are not exclusive breastfed because the mother still provides additional foods such as water / mineral water, some give honey as a tradition of local custom. Almost all of the purified exclusive breastfeeding without any given to infants of 40 respondents. Suggestion, toDehasen Bengkulu Midwifery Academy hopefully this research can be used as a reference material and additional reading in library, for Talang Leak health center it can be an input and information material for officer in giving counseling about exclusive breastfeeding on infant 6-12 months, for the researcher, as benchmark to apply the implementation of exclusive breastfeeding in infants 6-12 months.

\section{Keywords: exclusive breastfeeding}

\section{PENDAHULUAN}

Program kesehatan Indonesia pada penurunan Angka Kesakian dan kematian Bayi yang masih tinggi. Untuk menurunkan Angka kesakitan dan kematian Bayi, Menurut (WHO) Salah satunya yaitu bayi harus disusui Air Susu Ibu (ASI) saja paling lama enam bulan, sedangkan makanan tambahan diberikan lebih dari enam bulan, dan pemberian ASI seharusnya dilanjutkan sampai bayi berumur dua tahun.

Indikator untuk menentukan derajat kesehatan masyarakat Indonesia adalah ditandai dengan tinggi rendahnya angka kematian ibu (AKI) dan angka kematian Bayi (AKB) yang mempunyai pengaruh besar terhadap keberhasilan pembangunan nasional. Disamping itu peningkatan kualitas manusia harus dimulai sedini mungkin menjadi faktor yang memegang peranan penting dalam peningkatan kualitas manusia melalui pemberian ASI. ASI merupakan peranan penting bagi bayi dalam memulai kehidupan. Pemberian ASI eksklusif selama 6 bulan pada bayi akan meningkatkan drajat kesehatan, sehingga mengurangi AKB dan terbentuknya manusia yang berkualitas (Saleha,2009).

Berdasarkan data dari United Nations children's (UNICEF) pada tahun 2014 hanya $39 \%$ bayi di bawah usia 6 bulan yang mendapatkan ASI (Air Susu Ibu) secara Eksklusif di seluruh dunia, angka tersebut juga tidak mengalami kenaikan pada tahun 2016, yaitu hanya 40\% keberhasilan pemberian ASI Eksklusif di seluruh dunia.

Hasil survey Demografi dan Kesehatan Indonesia (SDKI) tahun 2013 menyebutkan di Indonesia hanya sepertiga $(42 \%)$ bayi berumur dibawah enam bulan yang mendapatkan ASI eksklusif. Diantara sepuluh hanya empat bayi yang berumur dibawah empat bulan $(54 \%)$ yang mendapatkan ASI eksklusif, dan hanya (46\%) anak umur kurang dari dua bulan mendapatkan ASI eksklusif (Depkes RI, 2007).

Pada data yang diberikan Dinas Kesehatan Provinsi Bengkulu menunjukkan bahwa jumlah bayi yang diberi ASI Eksklusif tertinggi yaitu wilayah Lebong 2.573 (74\%), dan yang terendah Kota Bengkulu 1.376 (38\%). Untuk wilaya Lebong, Puskesmas yang memiliki ASI ekslusif tertinggi yaitu Muara Aman sebesar 234 bayi (82,7\%), Sedangkan Puskesmas yang memiliki cakupan ASI Eksklusif terendah di Puskesmas Talang Leak yaitu hanya 40 bayi (54\%). Target yang ingin dicapai pada visi Indonesia sehat 2010 adalah sebesar 80\% (Dinkes Provinsi Bengkulu, 2016).

Dari latar belakang diatas peneliti tertarik melakukan penelitian tentang Gambaran Pelaksanaan Pemberian ASI Eksklusif pada Bayi usia 6-12 bulan di wilayah kerja Puskesmas Talang leak Kabupaten Lebong Tahun 2017. 


\section{TUJUAN PENELITIAN}

Tujuan umum dari penelitian ini adalah untuk melihat pelaksanaan pemberian ASI Eksklusif pada bayi usia 6-12 bulan di wilayah kerja puskesmas Talang Leak Kabupaten Lebong tahun 2017.

\section{METODE PENELITIAN}

Desain penelitian yang digunakan adalah deskriptif, untuk mengetahui gambaran pemberian ASI eksklusif pada bayi 6-12 bulan di desa Talang Leak jenis penelitian ini adalah kuantitatif. Populasi dalam penelitian ini adalah keseluruhan ibu yang mempunyai bayi berusia $6-12$ bulan yang menyusui dari bulan maret samapi juni tahun 2017 di wilayah kerja puskesmas Talang Leak Kabupaten Lebong sebanyak 40 bayi.

Sampel dalam penelitian ini diambil dengan menggunakan tehnik Total Sampling yaitu pengambilan sampel secara keseluruhan ibu yang mempunyai bayi usia 6-12 bulan yang menyusui berjumlah 40 bayi. Kriteria inklusi :Ibu yang memiliki bayi 6-12 bulan, Bayi ASI Ekslusif dan berada diwilayah kerja puskesmas talang leak, kabupaten lebong.

Kriteria eksklusi : ibu yang memiliki bayi $<6$ bulan, bayi yang tidak ASI Ekslusif, tidak diwilayah kerja puskesmas talang leak, kabupaten lebong.

\section{HASIL PENELITIAN}

Tabel 1. Distribusi Frekuensi ASI Ekslusif Pada Bayi 6-12 Bulan Di Puskesmas Talang Leak Kabupaten Lebong Tahun 2017

\begin{tabular}{lccc}
\hline No & Pemberian ASI & F & $\mathbf{\%}$ \\
\hline 1. & Tidak ASI Eksklusif & 9 & $22.5 \%$ \\
\hline 2. & ASI Eksklusif & 31 & $77.5 \%$ \\
\hline & Jumlah & 40 & 100 \\
\hline
\end{tabular}

Hasil penelitian yang telah dilakukan di Puskesmas Talang Leak, Lebong mengenai gambaran pelaksanaan pemberian ASI ekslusif pada bayi 6-12 bulan yang ada sebagai berikut bahwa dari 40 responden, hampir setengah bayi $(22,5 \%)$ yang tidak ASI Eksklusif. Dan Hampir Seluruh bayi (77,5\%) yang ASI Eksklusif.

\section{PEMBAHASAN}

Hasil penelitian yang dilakukan di Puskesmas Talang Leak, Kabupaten Lebong Tahun 2017 hampir setengah bayi yang tidak asi ekslusif dikarenakan ibu masih memberi makanan tambahan seperti air putih/air mineral, ada yang memberikan madu sebagai tradisi adat setempat.

Faktor yang Mempengaruhi Pemberian ASIEksklusif yaitu Pengetahuan Tentang pentingnya ASI, Perilaku ibu terhadap pemberian ASI dipengaruhi oleh beberapa faktor antara lain: Pengetahuan keyakinan, nilai yang di anut ibu tentang pemberian ASI yang benar akan menunjang keberhasilan menyusui. Pengetahuan ibu akan meningkat berkat pendidikan yang akhirnya akan berdampak pada peningkatan gizi dan kesehatan masyarakat akan meningkatkan produktifitas dan kualitas kerja dan kesejahteraan penduduk.

Kegagalan pemberian ASI eksklusif, Pada penelitian ini didapatkan bahwa pada bayi-bayi yang tidak mendapatkan ASI secara eksklusif selama 6 bulan sejak lahir. Kurangnya pengetahuan ibu tentang ASI, belum di pahaminya ASI secara tepat dan benar oleh ibu dan keluarga/lingkungan, Rintangan lain pada ibu menyusui adalah ibu menyusui tidak dibekali pengetahuan yang cukup tentang tehnik menyusui yang benar dan manajemen laktasi.

Dari Faktor yang Mempengaruhi Pemberian ASIEksklusif yaitu pengetahuan, maka penelitian ini sejalan dengan penelitian Arisma (2014) dengan judul faktor penyebab kegagalan pemberian ASI ekslusif yang dilakukan di Puskesmas Kedungmundu, Kecamatan Rowosari, Surabaya, yaitu rendahnya pengetahuan ibu tentang ASI Eksklusif, faktor pendorong berhasilnya ASI Eksklusif berupa pengetahuan dan motivasi 
ibu bersifat positif, faktor penguat berupa peran tenaga kesehatan, keluarga harus bersifat positif. Faktor penghambatnya berupa keyakinan yang keliru tentang makanan bayi yang menyebabkan gagalnya pemberian ASI Eksklusif.

Berdasarkan teori, ASI Eksklusif adalah menyusu bayi secara murni, yang dimaksud murni adalah bayi harus di berikan ASI saja tanpa diberikan makanan tambahan selama 6 bulan. Air Susu Ibu (ASI) adalah mekanan terbaik bagi bayi karena mengandung zat gizi yang paling sesuai untuk pertumbuhan dan perkembangan bayi yang optimal, ASI Eksklusif perlu diberikan sampai umur 6 bulan dan dapat dilanjutkan sampai anak berusia 2 tahun (KepMenKes,2011).

\section{KESIMPULAN}

Dapat disimpulkan bahwa dari pelaksanaan pemberian ASI ekslusif yang telah dilakukan dipuskesmas talang leak, hasil penelitian menunjukan bahwa dari 40 responden, hampir setengah bayi $(22,5 \%)$ yang tidak ASI Eksklusif, dan hampir seluruh bayi $(77,5 \%)$ yang ASI Eksklusif. Dikarenakan masih terdapat ibu yang memberikan makanan tambahan pada bayi 612 bulan, seperti minum air putih, madu, bahkan bubur tidak ASI murni dari ibu saja.

\section{SARAN}

Penelitian ini diharapkan bagi pihak akademik agar hasil penelitian studi kasus ini dapat dipakai dan dijadikan bahan referensi dan bacaan tambahan diperpustakaan bagi mahasiswi/mahasiswa Akademi Kebidanan Dehasen Bengkulu, diharapkan pada pihak puskesmas sebagai masukan dan bahan informasi bagi petugas dalam memberikan penyuluhan tentang ASI ekslusif pada bayi 06 bulan dan sebagai tolak ukur atas kemampuan penulis agar dapat menerapkan pelaksanaan pemberian ASI ekslusif pada bayi 0-6 bulan.

\section{DAFTAR PUSTAKA}

Arisna, Dkk (2010) Konsep Kebidanan Yogjakarta : Graha Ilmu

Depmenkes (2011) Tentang Asi Ekslusif Pada Bayi Dibawah Umur 6 Bulan Jakarta : Egc

Deswani (2012) ASI Esklusif Pada Bayi Baru Lahir(Imd) Jakarta : Media Cetak

Depkes Ri (2012) Riset Tentang Pencapaian Asi Ekslusif Program Pemerintah Jakarta. Profil Program Depkes Ri.

Depkes Ri. 2015. Sistem Kesehatan Nasional. Jakarta

Harwono, Abdi (2012) Asi Ekslusif. Jogjakarta:Cetak Ygk

Maryani, Eni (2012) Tumbuh Kembang Bayi Jakarta:Ygk

Notoatmojo,S.(2013). Metode Penelitian Kesehatan, Jakarta:Rinekka Cipta

Nugroh, Taufan (2011) Buku Ajar Obstetri Mahasiswa Kebidanan. Jojgakarta : Nuha Medika

Prasetio Sunar, Dwi (2009). Cara Menyususi Yang Baik. Jakarta : Arcan

Profil Dinas Kesehatan Provinsi Bengkulu 2015

Profil Dinas Kabupaten Lebong Tahun 2016

Roesli, Utami. (2013). Buku Pintar Asi Ekslusi. Jakarta : Diva Press.

Roesli, Utami (2012) Mengenal Asi Eskslusi. Jakarta: Trubus Agriwidya.

Saleha, Ari (2010) Asi Ekslusif. Jakarta: Media Cetak Massa

Salmah, Dkk. (2015). Asuhan Kebidanan Antenatal. Jakarta:Egc

Sumarah, Widyaastuti (2008) Asuhan Kebidanan Pada Ibu Bersalin.Jogjakarta : Fitramaya.

Soetjiningsih.(2014). Tumbuh Kembang Bayi Dan Anak. Jakarta:Sugeng Seto

Tridianwahyuni.(2014).Pemberian Asi Pada Bayi 0-6 Bulan. Jakarta:Erlangga

Wawan. (2015). Asi Eklslusif. Yogjakarta:Nuha Medik.

Who, Unfpa, And The World Bank Estimates. Trends In Maternal Mortality:19902010. Geneva:Who:2012

Yuanita, Arisma (2014) jurnal skripsi dengan 
judul faktor penyebab kegagalan pemberian ASI Eksklusif. http///w.ft.jurnal.kesehatan.blokskip.

Diakses pada tanggal 5 Agustus jam 10,15 wib. 